\title{
IMAGEM E CONCEITO: a metáfora da caça na filosofia da renascença
}

\author{
Image and Concept: the metaphor of hunt in \\ the philosophy of renaissance
}

Luiz Carlos Bombassaro
Possui Licenciatura Plena em Filosofia pela Universidade de Caxias do Sul (1982), Mestrado
em Filosofia pela Universidade Federal do Rio Grande do Sul (1991) e Doutorado em
Filosofia pela Universidade de Kaiserslautern, Alemanha (2001). Atualmente é Professor
Adjunto da Universidade Federal do Rio Grande do Sul. Atua na área da Filosofia, com ênfase
em Epistemologia e História da Ciência, Filosofia na Renascença e Filosofia da Educação.
e-mail: lcbombassaro@ yahoo.com.br

\section{Resumo}

O discurso filosófico da Renascença é marcado pelo uso freqüente de uma linguagem simbólica na qual se destacam mitos e metáforas. Visando mostrar a intrínseca relação que se estabelece entre imagem e conceito no pensamento renascentista, este texto indica o sentido epistemológico que a metáfora da caça adquire especialmente nos escritos de Gregor Reisch, Nicolau de Cusa, Giordano Bruno e Michel de Montaigne, onde não somente a lógica mas a própria filosofia é entendida como um processo venatório.

Palavras-chave: Renascença; Metáfora; Conhecimento; Lógica. 


\section{Abstract}

The philosophical discussion of the Renaissance is marked by the frequent use of a symbolic language that emphasizes myths and metaphors. Visioning to show the intrinsic relation that is established between image and concept in the renaissantist thinking, this text indicates the epistemological concept, that the hunting metaphor acquires specially in the writings of Gregor Reisch, Nicolau de Cusa, Giodano Bruno and Michel de Montaigne, where not only the logic but the philophy itself is understood as a concern to hunting process

Keywords: Renaissance; Metaphor; Knowledge; Logic.

\section{Introdução}

Em sua Margarita philosophica [Pérola filosófica], famosa enciclopédia de caráter pedagógico, escrita no início do século XVI, o monge cartuxo Gregor Reisch (1467-1525) apresenta uma das mais difundidas concepções filosóficas da Renascença. ${ }^{1}$ Publicada em 1504 e reeditada inúmeras vezes no decorrer do século, a obra contém já no seu frontispício uma gravura de alto conteúdo simbólico para a compreensão do espírito da época: a representação do universo do saber, com destaque para a filosofia, acompanhada pelas sete artes liberais. Antecipando o conteúdo próprio daquele manual acadêmico, a gravura é muito mais que uma simples ilustração impressa na abertura do livro, especialmente porque nela vem apresentado um modo todo próprio de compreender a recepção do pensamento antigo e medieval,

1 Gostaria de agradecer a Herzog August Bibliothek de Wolfenbüttel (Alemanha) pelo apoio para um profícuo período de pesquisa, onde pude comparar as diferentes edições da obra de Gregor Reisch. Para uma análise da Margarita philosophica, ver de modo especial ANDREINI, Lucia. (Org.). Gregorius Reisch: Margarita philosophica nova. 3 tomi. Introducione di Lucia Andreini. Nachdruck der Grüninger-Ausgabe von 1508 mit einem Einleitungsband; Salzburg: Institut für Anglistik und Amerikanistik der Universität Salzburg, 2002, e BÜTTNER, Frank. Die Illustrationen der Margarita Philosophica des Gregor Reisch In: BÜTTNER, Frank; FRIEDRICH, Markus;ZEDELMAIER, Helmut.(Org.). Sammeln-Ordnen-Veranschaulichen. Zur Wissenskompilatorik in der Frühen Neuzeit. Münster: 2003, p. 269-300. 
associando as disciplinas com as autoridades de cada área do conhecimento. Ao mesmo tempo, a gravura também é um convite à compreensão e à superação da distância temporal que nos separa e nos vincula ao pensamento filosófico da Renascença.

Para o argumento que pretendemos desenvolver aqui, no entanto, a representação da filosofia e das artes liberais não pode ser tomada desde uma perspectiva ampla, dado o significado específico que cada uma das artes adquire no contexto da obra de Gregor Reisch. Nesse sentido, nossa atenção dirige-se para uma das diversas gravuras inseridas no corpo do livro, typus logice, pois a dela pode ser desenvolvida uma análise que nos remete a um dos temas centrais da filosofia renascentista: o uso da metáfora e a relação entre imagem e conceito como elementos constitutivos da filosofia da Renascença.

Ao abrir a parte que trata da lógica e da linguagem, a Margarita philosophica do religioso de Freiburg mostra a seguinte cena (ver figura 1): um caçador, adequadamente vestido, vai à caça. ${ }^{2}$ Devidamente armado e acompanhado por dois cães, que perseguem uma lebre, ele tem diante de si, à sua esquerda, uma floresta e atrás de si uma caverna. Presa ao corpo, o caçador traz uma espada. Com a mão direita, carrega um arco e, com a esquerda, leva à boca uma trompa, que sopra e da qual brotam duas rosas.

Essa breve descrição já bastaria para indicar que não se trata somente de uma bela imagem de caça, mas de uma representação pictórica com a finalidade de evocar algo muito distinto de uma cena de caça. Trata-se, na verdade, de uma imagem, de uma metáfora, à qual vem associado um conceito que é antes de tudo uma figuração da lógica e, ao mesmo tempo, uma representação da própria atividade filosófica. A filosofia vem apresentada metaforicamente como uma caça e o filósofo como um caçador. Trata-se de uma analogia fecunda na qual cada elemento imagem, elaborada com precisão de detalhes, adquire um significado específico para o vocabulário e para o imaginário renascentista. Por isso, talvez seja mesmo conveniente descrever ainda melhor os elementos simbólicos que constituem a gravura.

A cena da caça não está centrada somente nos protagonistas da ação venatória: o caçador, os cães e a lebre. A gravura também reconstrói o cenário no qual se passa a ação. Assim, a silva opinionum, selva de opiniões,

2 Embora a interpretação corrente refira-se a uma figura masculina, convém lembrar que todas as artes liberais eram representadas por figuras femininas. Por isso, não deixa de ser estranho apresentar o typus logice por um caçador. Penso que haveria boas razões em figurar a lógica com uma caçadora, dada a importância que assumia no imaginário da Renascença a presença de Diana, a antiga deusa da caça. 
constituída por árvores enormes e diferentes, representa o universo das grandes correntes da lógica medieval: albertistas, escotistas, occamistas e tomistas, às quais poderiam estar sendo acrescidas ainda árvores ramistas e lulistas, tornando mais espessa a floresta da lógica renascentista. No meio do caminho, há pedras e vegetação variada. As pedras parecem representar as falácias (fallaciae). A parva naturalia mostra-se em folhagens várias. Arbustos diversos e ervas daninhas representam os insolubilia e os obligatoria, complicadas questões lógicas até então ou definitivamente sem solução. O elemento central da cena, no entanto, continua sendo a imponente figura do caçador. Em movimento, ele lança seus cães, falsitas e veritas (verdade e falsidade), ao encalço de uma presa em fuga, uma lebre (problema). Vestido a caráter, ele calça as botas praedicamenta e praedicabili (predicados e predicáveis), porta o arco da quaestio (questão) e a espada do syllogismus (silogismo), sonus e vox constituem seu instrumento de sopro, do qual brotam duas rosas como praemissae (premissas); o braço que segura seu instrumento leva o nome de argumenta (argumento) e em seu peito vem apresentada a conclusio (solução). ${ }^{3}$

Uma interpretação adequada desta gravura deveria poder explicitar sua riqueza expressiva e sua complexidade temática, para além de sua aparente simplicidade. Mas uma hermenêutica da imagem talvez possa se tornar efetiva somente mediante a introdução de uma nova perspectiva iconológica na filosofia. De todo modo, a interpretação da impressionante gravura já surge quando o próprio Reisch examina conceitualmente a questão da lógica e da linguagem no corpo do texto enciclopédico. Nas palavras de Reisch, a segunda parte do livro pretende esclarecer os fundamentos da dialética por meio de uma explicação exemplar. Ali, então, são descritas as várias partes da lógica, os predicados e os predicáveis, a estrutura da proposição, mas também são apresentados e analisados vários tipos de silogismo. ${ }^{4}$ Assim, em sua Margarita philosophica, Reisch funde imagem e conceito, de modo que se torna inevitável a remissão recíproca entre a figura e a descrição, não deixando margem à dúvida quanto ao significado que a imagem evoca. Ao referir-se à lógica como caça, a imagem constitui uma referência clara a um dos elementos centrais da filosofia.

\footnotetext{
Descrição semelhante desta gravura foi apresentada por PRANTL, Carl. Geschichte der Logik im Abendland. Leipzig, 1870. Ver também SCHNEIDER, Ulrich Johannes. (Org.). Seine Welt Wissen. Enziklopädien in der Frühen Neuzeit. Katalog zur Austellung der Universitätsbibliothek Leipzig (Januar-April 2006) und der Herzog August Bibliothek Wolfenbüttel (Juni-November 2006), Darmstadt: WBG, 2006, p. 193.

4 Sobre a doutrina do silogismo na filosofia renascentista, ver NEUSER, W. 'O silogismo e a matemática na ciência natural durante o Renascimento', In: BOMBASSARO, L. C; PAVIANI, J. (Org.). Filosofia, lógica e existência. Homenagem a Antonio Carlos Kroeff Soares. Caxias do Sul: Educs, 1997, p. 242-255.
}

Rev. Filos., v. 19, n. 24, p. 11-33, jan./jun. 2007 
Como pretendemos demonstrar, esta forma de apresentar a filosofia não é exclusividade da obra de Reisch, nem se trata de uma bela intuição ou de uma forma inusitada de representação pictórica das bases do pensamento filosófico renascentista. Antes de ser atribuído à mente brilhante de um monge cartuxo, este modo imaginativo de mostrar a filosofia deve ser creditado ao espírito da época. Na filosofia da Renascença, metáforas e múltiplas figuras de linguagem, carregadas de forte expressividade simbólica, juntam-se ao tratamento analítico e conceitual, criando níveis diferenciados de significação num léxico pleno de variações. Essa variabilidade de léxico e figuras, imagens e conceitos é provavelmente uma das características mais marcantes do discurso filosófico renascentista e, por si só, não deixa de ser fascinante. Mas é preciso ter presente que isso traz consigo as consequiências próprias da fascinação. $\mathrm{O}$ encanto, o desafio e o perigo inerentes aos textos e às gravuras da época capturam e podem também desorientar o leitor acostumado a dissociar a expressividade do pensamento figurativo e a analiticidade do pensar conceitual. Nesse sentido, aquele que se dedica ao estudo da filosofia da Renascença percebe, desde logo, que o acesso ao mundo do pensar da época pressupõe a impossibilidade de separar imagem e conceito e que especialmente o uso da metáfora é parte constitutiva do discurso filosófico. Embora possa parecer uma observação quase trivial, essa é de fato uma regra hermenêutica básica para a leitura e a interpretação dos textos filosóficos daquela época. Por isso, sem atentar para o uso e o significado das metáforas e das imagens simbólicas, a filosofia da Renascença corre o risco de se tornar um discurso esotérico, às vezes totalmente incompreensível.

A aproximação à filosofia renascentista pressupõe, portanto, ter reconhecer que uma reflexão sobre a presença da metáfora, sua possibilidade de uso e seu significado para a atividade de pensar, vem acompanhando o discurso filosófico praticamente desde sua origem. ${ }^{5}$ Nos últimos tempos, a questão ganhou ainda maior relevância, especialmente quando o problema foi melhor percebido e uma teoria consistente sobre o uso e o significado da metáfora na filosofia foi elaborada por Hans Blumenberg, um dos grandes

\footnotetext{
${ }^{5}$ Não é objeto deste texto uma reconstrução do horizonte sobre o qual se realizaram os mais recentes estudos sobre o papel da metáfora na filosofia. No entanto, cumpre ressaltar que impulsos decisivos para o estudo do uso e do significado da metáfora para o pensamento filosófico têm origem diversa. Sausurre, a Escola de Kopenhagen, Hjelmslev, Greimas, Derbolav, Lakoff e Johnson, além de Ricoeur e Gadamer, Davidson e Goodman, devem ser citados como referência, mesmo sabendo-se da incompletude da lista de autores que se ocuparam com essa questão.
} 
estudiosos atuais do pensamento renascentista. ${ }^{6}$ Em seus diversos estudos sobre o tema, Blumenberg mostrou, de modo convincente, não somente que as metáforas estão na base da filosofia ocidental, mas também como elas ganham validade e legitimidade no discurso filosófico. Como base para sua metaforologia, Blumenberg considerou especialmente a metáfora da luz. ${ }^{7}$ Suas teses, no entanto, foram levadas ainda mais adiante pelos recentes estudos de Bernhard Taureck, que propôs uma releitura da filosofia e suas metáforas com base numa iconologia crítica. ${ }^{8}$ Para Taureck, a metáfora não tem unicamente uma função didática e ornamental, o que aproximaria o discurso filosófico da poesia, mas tem o poder pragmático de desencadear o pensamento e constituir o núcleo expressivo da própria reflexão filosófica. ${ }^{9}$ Nesse sentido, além de um papel ilustrativo, a metáfora tem uma função heurística para a filosofia.

Tendo presente as gravuras da Margarita philosophica e considerando de modo especial aquela que apresenta a lógica, podemos agora avançar em nossa argumentação e mostrar como a metáfora da caça tem uma força expressiva que a torna um dos elementos simbólicos mais significativos para a compreensão da filosofia na Renascença. Como veremos, para além da enciclopédia filosófica de Gregor Reisch, para os filósofos da Renascença, a própria concepção de filosofia dependerá da interpretação da metáfora da caça. A validade dessa afirmação pode ser averiguada recorrendo aos textos filosóficos nos quais a metáfora da caça assume um papel central. Nesse sentido, mesmo que brevemente, mas de modo exemplar, pretendemos mostrar como o uso e o significado assumido pela metáfora da caça aparece em alguns dos mais importantes escritos filosóficos da época.

Como sabemos, a caça foi um dos temas e práticas preferidas da Renascença. Não somente como parte da cultura popular, especialmente presente na vida das cortes, mas também como motivo para múltiplas formas de manifestação do espírito humano, desde as artes em geral, como a pintura, a escultura e a música, até a literatura e o discurso filosófico, a caça exerceu uma

6 BLUMENBERG, Hans. Paradigmen zu einer Metaphorologie. (Archiv für Begriffsgeschichte). Bausteine zu einen historischen Wörterbuch der Philosophie 6 (1960), p. 5-142.

7 BLUMENBERG, Hans. 'Licht als metapher der Wahrheit. Im Vorfeld der philosophischen Begriffsbildung'. In: Studium Generale 10, (1957), p. 432-447.

8 ver especialmente TAURECK, Bernhard. Metaphern und Gleichnisse in der Philosophie. Frankfurt am Main: Suhrkamp, 2004.

9 TAURECK, Bernhard. Metaphern und Gleichnisse in der Philosophie. Frankfurt am Main: Suhrkamp, 2004, p. 159. Ver também TAURECK, Bernhard. Zwischen den Bilderni. Metaphernkritische Essays über Liberalismus und Revolution. Hamburg: Merus, 2006, onde o autor analisa o potencial revolucionário das metáforas no âmbito político. 
verdadeira fascinação durante a Renascença. Para poder compreender o alcance e a profundidade desse fenômeno, é necessário ter presente que, à época, a caça era essencialmente entendida e exercida como um privilégio real. Estava associada diretamente a uma das mais refinadas formas de lazer dos nobres e era por eles praticada de modo quase frenético. No entanto, para além desta dimensão cultural, na Renascença, a caça assumia um significado específico em outros dois âmbitos do saber humano. Por um lado, era uma das artes mechanicae, definindo assim uma área de conhecimento e um conjunto de práticas sociais, com consequiências diretamente associadas às discussões de caráter ético-moral. Por outro lado, como uma expressão cheia de significado simbólico, a caça era entendida como metáfora, assumindo um papel central na arte e na literatura, tanto com referência ao sagrado, como no caso dos manuais teológicos, quanto com referência ao espírito profano, como no caso da poesia cortesã. Desse modo, na Renascença, a caça ultrapassa o limite de uma prática cultural e de uma disciplina especial situada no interior do conjunto das artes mecânicas, para se tornar um dos componentes da produção simbólica e do imaginário da época. Não bastasse isso, a palavra caça assume um significado metafórico específico quando passa a ser usada como sinônimo de processo de investigação e de pesquisa. Nesse sentido, o uso metafórico da expressão encontra ressonância desde o conhecimento ordinário e cotidiano até a medicina, a teologia e a filosofia. ${ }^{10}$ Especialmente na filosofia, a caça ocupou o centro das discussões em torno das condições ético-morais da humanidade levadas a efeito nas reflexões de Erasmo, Maquiavel, Thomas More, Agrippa de Nettesheim e muitos outros. No entanto, foi nos escritos de Nicolau de Cusa, Giordano Bruno e Michel de Montaigne que a caça enquanto metáfora adquiriu um significado epistemológico específico, passando a ser usada para designar a própria atividade filosófica.

\section{A metáfora da caça em Nicolau de Cusa}

Nicolau de Cusa (1401-1464), nascido às margens do rio Mosel, tornou-se, não por acaso, um grande articulador político do catolicismo da

$10 \mathrm{Na}$ Medicina, por exemplo, a palavra venatio adquiriu um significado epistemológico particular especialmente na obra de Balduinus Ronsseus (Venatio medica [...], 1589). Com um significado totalmente diferente, a palavra venatio foi usada na Teologia como um recurso retórico constantemente disponível nas exortações e homilias. Nesse sentido, bastaria fazer referência às obras de Hadrianus Chrysogoni, Nicolaus Rehban e Benedictus Haeftenus.

Rev. Filos., v. 19, n. 24, p. 11-33, jan./jun. 2007 
primeira metade do século $\mathrm{XV}$, e também o primeiro dentre os grandes filósofos da Renascença. Para ele, como bem mostrou Ernst Cassirer, a pergunta pelo conhecimento adquiria uma posição de proeminência na filosofia. ${ }^{11}$

Associado a uma longa tradição filosófica, Nicolau de Cusa está primeiramente interessado em saber se e em que medida podemos confiar no conhecimento que nós mesmos produzimos. Sua pergunta refere-se ao âmbito do conhecimento não objetificável e, por isso, adquire um caráter transcendental. Em sua doutrina da coincidência dos opostos, o Cusano procura mostrar que tudo é constituído pela contradição subsumida na unidade. De acordo com sua doutrina, na unidade efetiva-se a coincidência dos opostos. Na medida em que aspira a 'coincidentia oppositorum', o Cusano demonstra que essa unidade não objetificável do pensamento e da ação humana está estreitamente vinculada à unidade absoluta. Pelo poder do entendimento, o homem pode sim reconhecer a unidade na multiplicidade e o caráter contraditório do mundo. Nesse sentido, para Nicolau de Cusa, a doutrina da coincidência dos opostos deve impulsionar o homem no caminho da investigação da verdade, de modo que ele possa capturar a unidade infinita na multiplicidade fenomênica do mundo.

As reflexões de Nicolau de Cusa sobre a atividade filosófica colocam a metáfora da caça no centro de sua obra. Sobre sua própria experiência na busca da verdade, ele nos apresenta um relato em seu De venatione sapientiae [À caça da sabedoria], uma espécie de autobiografia intelectual. Escrita ao completar sessenta e um anos, nela aparece uma "uma pequena apresentação" daquilo que o próprio autor considerou uma "expedição à caça da sabedoria" ${ }^{12}$ O motivo central desta obra é a definição de filosofia como um processo de investigação semelhante à caça. Nas palavras de Nicolau de Cusa: "Nihil enim sunt philosophi nisi venatores sapientiae, quam quisque in lumine logicae sibi conatae suo modo investigat."13 Noutras palavras, para o Cusano, a filosofia é uma forma metafórica de caça e os filósofos nada mais são que caçadores em busca da sabedoria.

Quando consideramos a estrutura do De venatione, percebemos as similaridades que a autobiografia de Nicolau de Cusa tem com os tratados

11 CASSIRER., Ernst. Das Erkenntnisproblem in der Philosophie und Wissenschaft der neuren Zeit. Darmstandt, 1971.

12 KUES, Nikolaus von. 'De venatione sapientiae [Die Jagd nach der Weisheit]'. In: Philosophischtheologische Werke. Bd 4, Darmstadt, 2002, p. 2-3.

13 KUES, Nikolaus von. 2002, p. 11: "Os filosófos nada mais são pois que caçadores de sabedoria, que cada um investiga a seu modo, de acordo com o lume de seu próprio entendimento".

Rev. Filos., v. 19, n. 24, p. 11-33, jan./jun. 2007 
de caça, um gênero literário muito difundido na Renascença, embora seu texto não possa ser considerado um tratado de caça no sentido estrito da palavra. Trata-se de uma apresentação na qual vem descrita uma caça teorética e especulativa, cuja influência não se encontra somente na filosofia clássica, especialmente no âmbito da tradição neoplatônica, mas também se vincula à tradição mística, de modo especial aquela influenciada pela cabala judaica. Em seu livro, Nicolau de Cusa serve-se de uma linguagem própria do mundo venatório, também usada nos tratados renascentistas sobre a arte da memória. Assim, tal qual um tratado de caça, o livro é dividido em áreas e campos: primeiramente, como desde um posto de observação é apresentada a perspectiva geral sob a qual devem ser demarcados os campos de caça, depois se segue a delimitação e a demarcação das áreas de caça e, finalmente, é reunida a presa, objeto da caçada.

Com isso, o Cusano mostra claramente a analogia entre a atividade venatória e o processo cognoscitivo realizado pelo filósofo. Sua caçada está dividida em dez campos: o primeiro é o da douta ignorância (docta ignorantia); o segundo, o do poder-ser (possest); o terceiro, o do não-outro (non-aliud); o quarto, o campo da luz (lux); o quinto é o campo do louvor divino (laudis Dei); o sexto, o da unidade (unitatis); o sétimo é o campo da igualdade (aequalitas); o oitavo é o campo da relação (nexus); o nono campo de caça é o do limite (terminus); e, finalmente, o décimo campo de caça é o da ordem (ordo). A descrição dos dez campos mostra como a atividade filosófica guarda uma semelhança profunda com a atividade venatória. Isso também se torna claro quando, ao final do De venatione, Nicolau de Cusa escreve: "Com essa exposição, creio ter mostrado com todas as minhas forças o resultado de minha caçada de um conceito rude e ainda não depurado e ter apresentado a todo aquele que, melhor do que eu, gostaria de contemplar os mais altos segredos". ${ }^{14}$

Essa estreita ligação entre a filosofia e a caça também fica evidente pela relação que o pensamento de Nicolau de Cusa estabelece com a analogia entre conhecimento e alimento: "Cognitio est assimilatio", eis o moto da epistemologia do Cusano, de acordo com o qual todos nós desejamos alcançar a sabedoria para nos tornarmos imortais. Como já havia sugerido ao descrever sua caçada, a atividade filosófica atinge seu objetivo no momento em que o espírito humano encontra seu "alimento", no momento em que o caçador alcança sua presa. Nesse sentido, o ponto de partida do De venatione sapientiae é "a observação de que cada espécie tem uma capacidade própria para saber qual o

14 KUES, Nikolaus von. 2002, p. 178-179. 
alimento de que necessita para manter sua vida. A vida do espírito deseja um alimento espiritual, que consiste no saber e na sabedoria. Com o auxílio de seu desejo de conhecimento, o homem precisa buscar e investigar as razões para a caça na qual ele encontra o seu alimento espiritual." Toda analogia se justifica. Tal como o corpo, o espírito também necessita de um alimento. E, desse modo, tal como o caçador ao realizar sua caçada procura aplacar a fome do corpo, assim também o filósofo, por meio da atividade venatória de seu intelecto deseja encontrar uma presa que possa lhe servir de alimento ao espírito. Esse paralelismo entre a vida material e a vida espiritual encontra aqui sua expressão mais radical e se consolida na imagem do banquete intelectual.

No entender de Martin Thurner, a caça constitui um 'enigma', colocado por Nicolau de Cusa de modo peculiar como uma intermediação sensível da atividade reflexiva. ${ }^{15}$ Nesse sentido, os caminhos da caça apresentam as sempre renovadas tentativas do espírito em encontrar a fonte originária de sua vida. Os campos de caça são a imagem que constituem os limites do mundo. O homem lança-se para o infinito com o objetivo de poder apreendê-lo. Mas o Cusano consegue tornar ainda mais claro o enigma da caça, ao indicar que o processo intelectual tem por fim um gozo afetivo. Quando Nicolau de Cusa cria uma imagem sensível da sabedoria como presa da caça, ele quer dizer com isso que a verdade do espírito é um objeto da vivência emocional, pois na caça toda espécie procura o alimento para sua vida, que pode ser saboreado com todos os sentidos. No caminho da sabedoria filosófica, que de acordo com sua etimologia é sapida scientia, um conhecimento que tem sabor, o Cusano pretende finalmente conquistar o gozo da vida divina. Desse modo, podemos afirmar que na obra de Nicolau de Cusa a metáfora da caça fornece uma imagem cujo significado consiste em esclarecer o modo como se realiza processo cognoscitivo que se efetiva na atividade filosófica, na busca que leva à sabedoria.

A enorme repercussão que o De venatione encontrou na Renascença certamente se faz sentir na Margarita de Reisch. Provavelmente tenha sido a autobiografia do cardeal de Cusa a fonte de inspiração que levou o monge cartuxo de Freiburg a identificar a lógica com uma forma específica de caça. No entanto, a influência do De venatione iria ainda muito mais longe e sua concepção filosófica ganharia maior densidade ao ser recebida no final do século XVI pelo pensamento de Giordano Bruno.

15 THURNER, Martin. 'Die Sinnlichkeit als Selbstdarstellung des Geistes: Die 'Aenigmata' des Cusanus'. In: Recherches de Théologie et Philosophie médiévales. (LXXI), 2004, p. 386-387. 


\section{A metáfora da caça em Giordano Bruno}

Na obra literária e filosófica de Giordano Bruno (1548-1600), um dos maiores filósofos da Renascença, a metáfora da caça desempenha um papel de primeira grandeza. Em Bruno, a metáfora da caça define a própria filosofia e adquire um caráter epistemológico específico, ao apresentar um método, de acordo com o qual vem descrito o processo de desenvolvimento da atividade intelectual. Com o uso da metáfora da caça, Bruno mostra de modo marcante e intensivo que sua concepção filosófica está em estreita conexão com as posições de Nicolau de Cusa. Mas Bruno vai muito além do Cusano, ao transformar a metáfora da caça em elemento constitutivo de sua concepção filosófica, envolvendo tanto aspectos inerentes a sua teoria do conhecimento quanto questões de caráter ético e moral. Até mesmo sua biografia guarda uma relação direta com os elementos que ele havia tematizado em sua filosofia, de modo que em Bruno a vida e a experiência filosófica coincidem. ${ }^{16}$

Quando se trata de questões epistemológicas, os filósofos comumente procuram apresentar seus argumentos em forma de tratados, sumas ou diálogos. Um caso muito especial é o que ocorre com Giordano Bruno em seu diálogo De gli eroici furori, composto por sonetos e comentários em prosa, onde o autor se serve dos mais variados e significativos meios estilísticos para apresentar sua filosofia e dar corpo ao seu pensamento. Nesse escrito bruniano estrutura-se uma argumentação que geralmente parte de imagens, mitos e metáforas culminando num discurso analítico em cujo centro se encontram conceitos e definições. Mas ao fazer a apresentação de sua filosofia, Bruno prefere fazer uso de uma linguagem cheia de analogias e de metáforas. Isto, no entanto, não significa que a racionalidade do texto bruniano possa ser posta em dúvida. Aqui vale antes o contrário. A racionalidade do texto completa-se em sua construção por meio do uso de uma linguagem pictórica, cuja lógica interna é constituída pelos símbolos e pelas imagens. Na obra filosófico-literária de Bruno, o importante está exatamente nesse movimento entre a imagem e o conceito. Nesse sentido, em seus escritos, o uso das metáforas é uma constante e por meio de um processo analógico, Bruno pode integrar, por um lado, os conceitos às imagens e, por outro lado, as formas sensíveis ao discurso analítico. Desse modo, as imagens e as metáforas adquirem na obra bruniana uma força reflexiva sem precedentes no pensamento filosófico.

16 Sobre o tema ver especialmente ORDINE, Nuccio. O umbral da sombra: Filosofia, literatura e pintura em Giordano Bruno. São Paulo: Perspectiva, 2006. 
Dentre as inúmeras metáforas usadas por Bruno, a metáfora da caça é aquela que certamente adquire o maior significado e aquela que reflete com maior clareza a força de compreensão da atividade intelectual. Juntamente com as metáforas, os escritos brunianos são permeados por mitos, dos quais Bruno se serve para transformar em imagem os conceitos filosóficos que adota. Assim, dentre os inúmeros mitos usados por Bruno encontramos aquele que é provavelmente $\mathrm{o}$ mais expressivo, o mito de Ácteon, que associado à metáfora da caça servirá para apresentar e tematizar não somente as possibilidades e os limites da vontade e do intelecto, mas também a própria concepção bruniana de filosofia. A metáfora da caça e o mito de Ácteon são usados por Bruno para representar de forma simbólica o processo volitivo e a atividade do intelecto humano. Com o uso desse mito e dessa metáfora, Bruno formula simbólica e figurativamente sua concepção filosófica e apresenta uma descrição do próprio processo vivido pelo filósofo.

Uma resposta minimamente satisfatória à pergunta - por que Bruno faz uso de mitos e metáforas para apresentar seu pensamento - funda-se provavelmente no fato de que ele, em sua obra filosófica, incorpora uma importante tradição poética e literária, aquela dos tratados amorosos. Em Bruno ressoam os efeitos dessa tradição, presentes em seu estilo literário, tanto em prosa quanto em verso. Dentre os autores antigos poucos foram aqueles que não fizeram uso de mitos e metáforas. Somente para citar dois autores que tiveram uma profunda influência no pensamento e na obra do Nolano, basta lembrar Platão e Ovídio. Tal como nos autores clássicos da Antigüidade, também em Bruno os mitos e as metáforas caracterizam-se por uma enorme força expressiva e vêm carregados de múltiplos significados.

A caça foi sem dúvida um dos mais freqüentes motivos da literatura antiga. Para os poetas gregos Hesíodo e Homero, e de modo especial para os trágicos Sófocles, Ésquilo e Eurípides, a caça constituía um tema importante, freqüentemente apresentado e tematizado por mitos. Desde Hesíodo, por exemplo, a literatura antiga conhece, em diversas versões, o mito de Ácteon. Dentre essas versões, a mais conhecida é provavelmente aquela em que Ácteon vem apresentado como um caçador solitário, que se apaixona por Semele e que, por isso mesmo, atrai para si o ciúme e a ira de Zeus, que por sua vez o castiga, fazendo com que seja morto por Artemis durante uma caçada. O destino trágico de Ácteon permanecerá com algumas pequenas variantes também nas narrativas posteriores, quando a deusa da caça se sente ofendida por ter sido por ele inadvertidamente surpreendida no banho com suas ninfas. Uma variante dessa última versão contada por Ovídio foi a mais difundida na literatura da Renascença e constitui provavelmente a fonte de inspiração bruniana. 
Ovídio relata o mito de Ácteon no terceiro livro de suas Metamorfoses. Na versão de Ovídio, para se recuperar de uma caçada, Diana retira-se para um banho junto a uma fonte natural, acompanhada por suas ninfas. Enquanto se banha, Ácteon - que procurava sua presa na floresta - depara inesperadamente com a fonte, onde vê Diana nua. Nesse momento, Diana borrifa água no rosto de Ácteon, transformando-o num cervo, que é imediatamente devorado pelos seus cães. Essa versão do mito de Ácteon, recebida e constantemente reelaborada na Renascença, tornou-se motivo central não somente para a literatura, mas também para a escultura e a pintura. Mas foi Giordano Bruno quem introduziu Diana e Ateon no mundo filosófico, transformando-os em elementos centrais de seu pensamento.

No final do quarto diálogo da primeira parte dos Eroici furori, Bruno apresenta do seguinte modo sua versão do mito de Ácteon:

Alle selve i mastini e $i$ veltri slaccia

Il giovan Atteon, quand'il destino

Gli drizz'il dubio ed incauto camino,

Di boscareccie fiere appo la traccia.

Ecco tra l'acqui il piú bel busto e faccia,

Che ver poss'il mortal e divino,

In ostro ed alabastro ed oro fino,

Vedde; e 'l gran cacciator dovenne caccia.

Il cervio ch'a' piú folti

Luoghi drizzav'i passi piú leggieri,

Ratto vorâro i suoi gran cani e molti.

I' allargo i miei pensieri

Ad alta preda, ed essi a me rivolti

Morte mi dàn con morsi crudi e fieri. ${ }^{17}$
Às selvas os mastins e os galgos lança

O jovem Ácteon, quando o destino

Leva-o por caminho duvidoso e incerto,

De feras selvagens seguindo o rastro.

Eis por entre as águas o mais belo busto e face,

Que possa ver o mortal e divino,

Em púrpura, alabastro e ouro fino;

E o grande caçador torna-se caça.

O cervo que aos lugares mais desertos

Dirigia seus passos mais ligeiros,

Foi devorado por seus cães grandes e muitos. Eu elevo meus pensamentos

À alta presa, e eles contra mim se voltam

E com golpes cruéis e violentos me matam. ${ }^{18}$

17 BRUNO, Giordano. 'De gli eroici furori'. In: Dialoghi italiani. Firenze: Sansoni, 1958. p. 1005-1006.

18 Tradução do autor.

Rev. Filos., v. 19, n. 24, p. 11-33, jan./jun. 2007 
Considerando a importância da metáfora da caça para a filosofia de Bruno, esse soneto deve ser considerado uma das passagens centrais de toda sua obra. ${ }^{19}$ Bruno introduz aqui a figura de Ácteon e apresenta, por meio dela, a doutrina da vontade e do intelecto, o que constitui na verdade o núcleo duro de sua filosofia. Por outro lado, ele levanta aqui uma questão central que desempenha um papel decisivo em seus escritos; uma questão cujo esclarecimento não auxilia somente a interpretação do soneto, mas contribui também para uma compreensão das bases da concepção bruniana de conhecimento. No seu comentário em prosa, que acrescenta ao soneto, Bruno escreve: "Ácteon ocupa aqui o lugar do intelecto". ${ }^{20}$ Ao identificar a figura central do soneto, Bruno faz uma indicação que deve ser considerada como o primeiro e mais decisivo passo hermenêutico para compreender o poema e o papel de Ácteon no conjunto de sua obra. Ao passar da linguagem metafórica para a linguagem conceitual, ele designa o tema filosófico que constitui o ponto central dos Eroici furori, que se desdobra ao longo do seu comentário em prosa. O elemento mais importante aqui é o caçador como uma figura poética, uma imagem que se torna um símbolo para representar a doutrina do intelecto e da vontade. Assim, por meio da interpretação fornecida pelo próprio Bruno, sabemos que Ácteon é concebido como figuração poética do intelecto. O caçador vê-se transformado em intelecto, por uma estratégia interpretativa, mas essa transformação é muito sugestiva, pois indica uma área limítrofe entre os dois níveis lingüísticos nos quais se move o filósofo de Nola.

A tarefa do intelecto consiste, pois, em alcançar a verdade, em "conquistar", "apreender", "capturar" a beleza e a sabedoria. Não por acaso, todos esses termos guardam uma semelhança profunda com o universo semântico da caça. Noutras palavras, o intelecto está à procura de conceitos ideais. Tal como o caçador, assim também o intelecto se torna atento e se concentra no objeto de sua caça. Nesse sentido, o intelecto se mostra mediante a atividade de apreensão (apprension) do objeto desejado. O conceito bruniano de intelecto está, portanto, longe de ser caracterizado por uma atitude passiva. Sua razão de ser está na atividade que realiza e lhe é inerente. Essa posição ultrapassa a concepção tradicional do intelecto adotada na filosofia medieval e reforça a tese da participação da vontade no processo cognoscitivo. No texto bruniano, a atividade do intelecto vem apresentada pelas palavras caça (caccia)

19 Apresentamos uma análise detalhada dessa posição em: BOMBASSARO, Luiz Carlos. Im Schatten der Diana: Die Jagdmetapher im Werk von Giordano Bruno. Frankfurt am Main, 2002, p. 311.

${ }^{20}$ BRUNO, 1958, p. 1006.

Rev. Filos., v. 19, n. 24, p. 11-33, jan./jun. 2007 
e apreensão, captura (apprension). Também por isso, pode-se reconhecer que a linguagem usada por Bruno para definir a atividade intelectual está fortemente associada à linguagem do mundo venatório. Nesse sentido, a imagem do caçador serve para descrever analogicamente de modo adequado e preciso a atividade do filósofo, que faz uso do intelecto em sua investigação, em sua busca da verdade. Por isso, em Bruno, o caçador Ácteon não representa somente o intelecto, mas representa também a própria figura do filósofo, enquanto o lugar tenente da capacidade de pensar. Tal como fora definido por Nicolau de Cusa, também para Bruno, a filosofia nada mais é senão uma forma de caça e o filósofo nada mais senão um caçador de sabedoria.

A imagem da caça também é usada por Bruno em outras passagens de sua obra, sempre referida a um modo metafórico de apresentar sua concepção da investigação filosófica. ${ }^{21}$ Essa contínua referência à metáfora da caça serve para mostrar, portanto, que, para Bruno, a caça fornece o modelo ideal de um método de investigação. No caso específico dos Eroici furori, o percurso realizado pelo filósofo para alcançar os conceitos universais, a verdade, a beleza, o bom e o uno, assemelha-se a uma caçada, com uma diferença básica em relação à atividade venatória do mundo empírico: a caçada realizada pelo filósofo nunca chega ao fim, porque sua presa é, ela mesma, inalcançável, inapreensível. Nesse sentido, o processo de investigação torna-se infinito. No livro De immenso, por exemplo, Bruno manterá essa posição e afirmará que "a pergunta e a investigação não se apagam com a consecução de uma verdade limitada e de um bem definido". Este ideal do progresso infinito poderia, aliás, situar-se dentro da tradição das representações antigas, platônicas ou estóicas, da sabedoria como estado de perfeição inacessível e do filósofo como alguém privado de sabedoria (portanto, como não-sábio), mas também, e ao mesmo tempo, como enamorado da sabedoria, como aquele que se lança em busca da sabedoria numa investigação sem fim. Caberia, portanto, definir a filosofia como uma atividade venatória que nunca se realiza plenamente e que, por sua vez, mantém-se constantemente em processo.

Por outro lado, - e isso demandaria uma análise específica, que não pode ser realizada aqui - o fim do processo venatório descrito por Bruno consiste na transformação do próprio caçador em caça. Em vez de apreender, o filósofo torna-se, ele próprio, a presa de seus pensamentos. No soneto bruniano, o destino de Ácteon revelaria o fim de toda atividade filosófica como uma metamorfose. Nisso, a concepção bruniana de filosofia parece estar bem próxima

21 Um inventário detalhado do uso da metáfora da caça nos escritos italianos e latinos de Bruno encontra-se em Luiz Carlos Bombassaro, 2002, p. 195. 
daquela antiga posição socrática, que em última análise compreendia o filosofar como uma forma de preparação para a morte, uma morte que vem interpretada pela tradição como um abandono de um determinado modo de ver e sentir em favor de uma forma diferenciada de compreensão.

Essa imagem bruniana do filosofar como um processo infinito e como uma forma de morte não está remetida somente às referências socráticas presentes no mito de Ácteon. Ela continuará a repercutir na filosofia da Renascença, mesmo sem a referência àquele mito. No entanto, parece que ela não se conseguirá destacar com facilidade da metáfora da caça, tal como foi o caso de Michel de Montaigne.

\section{A metáfora da caça em Michel de Montaigne}

Michel de Montaigne (1533-1592) é o terceiro exemplo que gostaria de citar no contexto dessa análise sobre o uso da metáfora da caça na filosofia do Renascimento. Diferentemente de Nicolau de Cusa e de Giordano Bruno, Montaigne prefere falar criticamente da filosofia partindo de uma perspectiva histórico-conceitual e acentuando especialmente os aspectos éticomorais da vida humana. Uma apresentação clara de sua concepção da filosofia Montaigne a faz por meio de seus Ensaios, de modo especial em sua Apologia de Raymond Sebond, onde reconstrói em grande medida as idéias antigas que mais o influenciaram. ${ }^{22}$ Dentre elas está a da relação entre o homem e a natureza, cuja mediação somente é possível pelo conhecimento. No entanto, também Montaigne assume uma concepção crítica em relação ao problema da atividade cognoscitiva, pois baseia suas concepções na indagação de como é possível estabelecer a relação entre o universo e o homem, uma vez que este é somente um fragmento do universo. Por isso, a resposta de Montaigne se voltará para a impossibilidade do homem em conhecer a totalidade do mundo, uma posição que o aproxima das posições do ceticismo antigo. Mas o centro das preocupações de Montaigne não é propriamente o mundo. Sua atenção se volta para si mesmo, para o próprio homem inserido no mundo. Ele mesmo é o centro de suas indagações filosóficas.

Quando se considera as afirmações de Montaigne sobre o conhecimento desde uma perspectiva mais ampla, pode-se chegar até mesmo a duvidar de que ele esteja defendendo posições céticas radicais, uma vez que

${ }^{22}$ MONTAIGNE, Michel de. Ensaios. (Os pensadores), São Paulo: Abril, 1972, p. 208. 
salienta o valor e a necessidade do conhecimento. "Amo e honro o saber, bem como os que o possuem: empregado com critério é a mais nobre e poderosa aquisição do homem," afirma numa das passagens centrais de sua obra. ${ }^{23}$ Evidentemente, essa afirmação em particular não pode ser usada para negar o tão propalado ceticismo daquele que foi também um dos maiores pensadores do final da Renascença. No entanto, também não é possível deixar de considerar que para Montaigne, o conhecimento é uma atividade essencial na caracterização do que há de mais específico para a vida humana, o desejo de saber. "O desejo de saber é o mais natural. Experimentamos todos os meios suscetíveis de satisfazê-lo, e quando a razão não basta apelamos para a experiência." ${ }^{24}$

Nesse sentido, podem ser compreendidas as constantes referências que Montaigne faz aos textos e aos autores antigos. Leitor mais assíduo de Sêneca e de Plutarco, do que de Platão e de Aristóteles, Montaigne tem como o principal objetivo de sua filosofia uma profunda análise de si próprio. Em seus Ensaios, escreve:

Há vários anos, somente a mim mesmo tenho como objetivo de meus pensamentos, somente a mim é que observo e estudo; se atento para outra coisa logo a aplico a mim ou a assimilo. E não creio seguir caminho errado se, como fazem com as outras ciências incontestavelmente menos úteis, comunico a outrem minhas experiências, embora me considere pouco satisfeito com meus progressos. ${ }^{25}$

A preocupação epistemológica primeira de Montaigne está diretamente relacionada com o conhecimento de si e em mostrar a dificuldade em penetrar as profundezas obscuras do espírito humano. Contudo, será exatamente na tematização do conhecimento que poderemos encontrar Montaigne usando as mais diferentes metáforas, dentre as quais está a metáfora da caça, que, de acordo com nossa perspectiva, está longe de desempenhar um papel secundário em sua obra filosófica.

Servindo-se de uma linguagem metafórica, própria da sua época e do seu ambiente intelectual, numa passagem central de seus Ensaios, Montaigne escreve: "A caça é de nossa alçada, não é desculpável que a conduzamos mal; quanto a errar o golpe é outra coisa. Não está, como dizia Demócrito, enterrada no fundo de um abismo; antes se eleva ao infinito até se

${ }^{23}$ MONTAIGNE, 1972, p. 424.

${ }^{24}$ MONTAIGNE, 1972, p. 481.

${ }^{25}$ MONTAIGNE, 1972, p. 182. 
tornar conhecida unicamente de Deus." ${ }^{26}$ Para Montaigne, toda investigação parece ter um valor em si mesmo e somente ela, enquanto processo de busca, importa ao filósofo. A perseguição e a caça são o verdadeiro propósito do filósofo. Sua atividade está remetida a um método, de cujo uso adequado depende o êxito da tarefa investigativa. Nesse sentido, Montaigne é implacável. Para ele, não há desculpas se a caça for mal praticada. Que ela seja malsucedida, que o filósofo-caçador possa falhar exatamente no momento da apreensão da presa já é outra coisa. O que realmente importa é a aplicação adequada do método. Que ele não seja ainda suficiente para alcançar a verdade, isso não diz respeito e não depende do filósofo, mas tem a ver como o objeto de sua caça. $\mathrm{O}$ fato é que o filósofo nasce para andar à procura da verdade, para procurar sua presa. Possuí-la, dirá Montaigne, diz respeito a uma potência bem maior.

Sobre esse desejo infinito de conhecer e sobre a interminável caça ao saber, Montaigne escreverá palavras ainda mais esclarecedoras: "Só por fraqueza nos contentamos com o que outros e nós mesmos deparamos nessa caça ao saber; os mais aptos não se satisfazem e haverá sempre caminho a percorrer para quem vier depois, e até para nós se agirmos de outro modo. Nossas investigações só chegarão ao fim no outro mundo." ${ }^{27}$ De um modo muito semelhante àquele descrito por Nicolau de Cusa e por Giordano Bruno, também para Montaigne a caça a sabedoria é uma atividade que não se esgota. Filosofar é estar sempre a caminho. Nesse sentido, se por um lado a admiração constitui a base da filosofia, por outro lado, o filosofar realiza-se como um processo contínuo que somente pode encontrar a provisoriedade e a incerteza ao seu final.

Esse destaque do filosofar, como um processo que nunca se esgota, é muito bem expresso uma vez mais quando Montaigne afirma que o filósofo nunca encontra a plena satisfação com o que alcança, não se contenta com o que apreendeu.

Contentar-se é sinal de falta de fôlego ou de lassidão. Nenhum espírito generoso se detém por si mesmo, antes vai sempre para diante e além de suas forças. Se não se afana, não se apressa, não acua, não se choca, não gira sobre si mesmo, é porque não está vivo, vegeta. Suas buscas não têm forma nem fim; alimenta-se de admiração, de pesquisas, de dúvidas [...] Trata-se de um movimento irregular, perpétuo, sem molde e sem objetivo, cujas invenções se estimulam, se sucedem e se criam mutuamente. ${ }^{28}$

${ }^{26}$ MONTAIGNE, 1972, p. 182.

${ }^{27}$ MONTAIGNE, 1972, p. 483.

${ }^{28}$ MONTAIGNE, 1972, p. 483.

Rev. Filos., v. 19, n. 24, p. 11-33, jan./jun. 2007 
O exercício de auto-superação, de transformação, marca assim uma atitude que parece fazer coincidir a atividade do filósofo e a atividade do caçador.

Para entender de modo ainda mais adequado a posição de Montaigne em relação ao uso da metáfora da caça convém, no entanto, ter presente também uma outra de suas afirmações lapidares. Após ter identificado o processo cognoscitivo com uma forma de caça, ao tratar da arte da conversação, o autor dos Ensaios afirma: "o mundo não passa de uma escola de investigação." ${ }^{29}$ Para Montaigne, toda a investigação que o homem realiza traz à mão a experiência vivencial do próprio investigador situado no mundo. Mundo aqui não tem uma conotação única e simplesmente empírica, que poderia ser descrito a partir de uma perspectiva fisicalista, mas revela a totalidade na qual se realiza a investigação humana. Descreve originariamente à experiência existencial do homem. O mundo é uma escola de investigação na qual se produz o conhecimento de si mesmo antes de se produzir o conhecimento do próprio mundo. Desse modo, mesmo que não se possa provar a hipótese de uma relação mais direta do pensamento de Bruno e aquele de Montaigne, vale a pena recordar que também para o Nolano, a pergunta e a investigação não se apagam com a consecução de uma verdade limitada e de um bem definido. Desse modo, tanto Nicolau de Cusa quanto Bruno poderia ser compreendidos como companheiros de Montaigne, no sentido de que ambos poderiam ser vistos como os verdadeiros filósofos-caçadores, que se aventuraram ir além dos limites da filosofia escolástica, para recuperar a antiga imagem do conhecimento como uma busca infinita de sabedoria.

\section{Considerações finais}

Após essa breve exposição, gostaria de concluir com algumas considerações que pretendem simplesmente apontar para a necessidade de investigação mais detalhada do uso da metáfora da caça nos textos filosóficos da Renascença e sua consequiência para uma compreensão adequada da imagem do processo cognoscitivo.

Em primeiro lugar é preciso ter presente que o uso da metáfora da caça está em consonância com o ambiente filosófico e cultural da Renascença. No ambiente das cortes e das academias reais, a filosofia era compreendida

${ }^{29}$ MONTAIGNE, 1972, p. 425. 
como uma atividade nobre, um jogo como aquele jogo próprio dos nobres. Nesse sentido, como pretendia a Margarita philosophica de Reisch, a imagem da caça servia exemplarmente como representação para a atividade filosófica. Isso constitui, por sua vez, uma mostra significativa daqueles elementos empíricos das quais partia a filosofia renascentista. É neste sentido que pode ser compreendido o uso da linguagem metafórica, carregada de símbolos, que não servia somente como ilustração, mas como elemento desencadeador do próprio pensamento filosófico, num ambiente que ia se tornando cada vez mais laico, fortemente influenciado pelo processo de secularização. Por isso, se Nicolau de Cusa ainda usa elementos teológicos para fazer referência a sua venatio, e se em Giordano Bruno esses elementos são substituídos por uma metafísica impregnada de elementos pagãos presentes no mito de Ácteon e associados ao discurso do amor cortesão e à vida na corte, na obra de Montaigne a metáfora da caça pretende livrar-se dos resquícios metafísicos, servindo simplesmente para descrever o processo cognoscitivo. Nesse sentido, poderíamos afirmar que, assim como Bruno seguiu as pistas fornecidas por Nicolau de Cusa, Montaigne segue as pistas oferecidas por Giordano Bruno e usa a metáfora da caça para aplicá-la à descrição da vida intelectual. Mas um aspecto ainda mais importante para a filosofia da Renascença é o significado epistemológico que a metáfora da caça traz consigo. Pode-se identificar no uso dessa metáfora uma pretensão dos autores analisados em descrever a atitude do sujeito cognoscente, mostrando o papel ativo do intelecto no processo de produção do conhecimento e do saber, marcador importante diante do papel passivo do intelecto, tão caro ao modelo do conhecimento revelado. Bruno falava que o homem não poderia ser considerado um vaso, um recipiente que acumulava o conhecimento infundido pela divindade dentro de si, um mero portador da palavra. Para Bruno, o homem era capaz de discurso próprio, de fazer uso da própria razão. Nesse sentido, a produtividade teórica do uso da metáfora da caça dá suporte às teorias cognitivas que defendem o papel ativo sujeito e tem uma consequiência direta no estabelecimento de modelos e métodos presentes no pensamento moderno, onde também ganha destaque a idéia do conhecimento como uma atividade permanente e uma obra que não chega ao fim, no sentido que nunca se conclui e que não atinge plenamente seu objetivo, mas está sempre em movimento, em construção.

Nesse sentido, ao analisar o uso da metáfora da caça na filosofia da Renasceça, percebe-se a consciência aguda que esses autores tinham da força simbólica e expressiva da linguagem metafórica, uma força capaz de superar os limites impostos pela análise conceitual. Esse aspecto merece 
destaque exatamente por se vincular àquela atividade pedagógica que não esgota suas potencialidades no exclusivo uso dos conceitos, como bem o mostrara Gregor Reisch. Embora a mentalidade objetivante da ciência moderna tenha exercido um poder incalculável na constituição da mentalidade pedagógica dos últimos séculos, o fato é que o uso da linguagem simbólica sempre foi imprescindível para o desenvolvimento da imaginação e do espírito criativo, possibilitando a passagem para o novo. Nesse sentido, o uso da metáfora pode ser destacado não somente como um recurso ilustrativo no processo pedagógico, mas também como um fator desencadeante da reflexão e do pensamento. Assim, a imagem da lógica como caça ressurge aqui não meramente como uma ilustração, mas como uma imagem exemplar que incita e promove a reflexão.

\section{Referências}

ANDREINI, Lucia (Org.). Gregorius Reisch: Margarita philosophica nova. Nachdruck der Grüninger-Ausgabe von 1508 mit einem Einleitungsband. Salzburg: Institut für Anglistik und Amerikanistik der Universität Salzburg, 2002.

BLUMENBERG, Hans. 'Licht als Metapher der Wahrheit. Im Vorfeld der philosophischen Begriffsbildung'. In: Heidelberg: Springer, 1957. p. 432-447. Studium Generale (10).

Paradigmen zu einer metaphorologie (Archiv für Begriffsgeschichte. Bausteine zu einen historischen Wörterbuch der Philosophie (6), Bonn: Bouvier, 1960. p. 5-142.

BOMBASSARO, Luiz Carlos. Im Schatten der Diana: Die Jagdmetapher im Werk von Giordano Bruno. Frankfurt am Main: Peter Lang, 2002.

BRUNO, Giordano. 'De gli eroici furori'. In: Dialoghi italiani. Firenze: Sansoni, 1958.

BÜTTNER, Frank. Die Illustrationen der Margarita Philosophica des Gregor Reisch. In: .; FRIEDRICH, Markus; ZEDELMEIER, Helmut (Org.).

Sammeln - Ordnen - Veranschaulichen: Zur Wissenskompilatorik in der Frühen Neuzeit. Münster: Lit, 2003. p. 269-300.

CASSIRER, Ernst Cassirer. Das Erkenntnisproblem in der Philosophie und Wissenschaft der neuren Zeit. Darmstandt: WBG, 1971. 
KUES, Nikolaus von. 'De venatione sapientiae [Die Jagd nach der Weisheit]' In: Philosophisch-theologische Werke. Bd 4, Darmstadt: WBG, 2002.

MONTAIGNE. Michel de. Ensaios. São Paulo: Abril Cultural, 1972. (Os pensadores).

NEUSER, Wolfgang. 'O silogismo e a Matemática na ciência natural durante o Renascimento'. In: BOMBASSARO, L. C.; PAVIANI, J. (Org.). Filosofia, lógica e existência. Homenagem a Antonio Carlos Kroeff Soares. Caxias do Sul: Educs, 1997. p. 242-255.

ORDINE, Nuccio. O umbral da sombra: filosofia, literatura e pintura em Giordano Bruno. São Paulo: Perspectiva, 2006.

PRANTL, Carl. Geschichte der Logik im Abendland. Leipzig: Teubner, 1870.

REISCH, Gregorius. Margarita philosophica. Argentorati: Grüninger, 1508.

SCHNEIDER, Ulrich Johannes (Org.). Seine Welt Wissen. Enziklopädien in der Frühen Neuzeit. Katalog zur Austellung der Universitätsbibliothek Leipzig (Januar-April 2006) und der Herzog August Bibliothek Wolfenbüttel (JuniNovember 2006), Darmstadt: WBG, 2006.

TAURECK, Bernhard. Metaphern und Gleichnisse in der Philosophie. Frankfurt am Main: Suhrkamp, 2004.

Zwischen den Bildern. Metaphernkritische Essays über Liberalismus und Revolution. Hamburg: Merus, 2006.

THURNER, Martin. 'Die Sinnlichkeit als Selbstdarstellung des Geistes: Die 'Aenigmata' des Cusanus'. In: Recherches de Théologie et Philosophie médiévales. (LXXI), Freiburg: Peeters, 2004. p. 372-395. 
ANEXO A - Typus logice

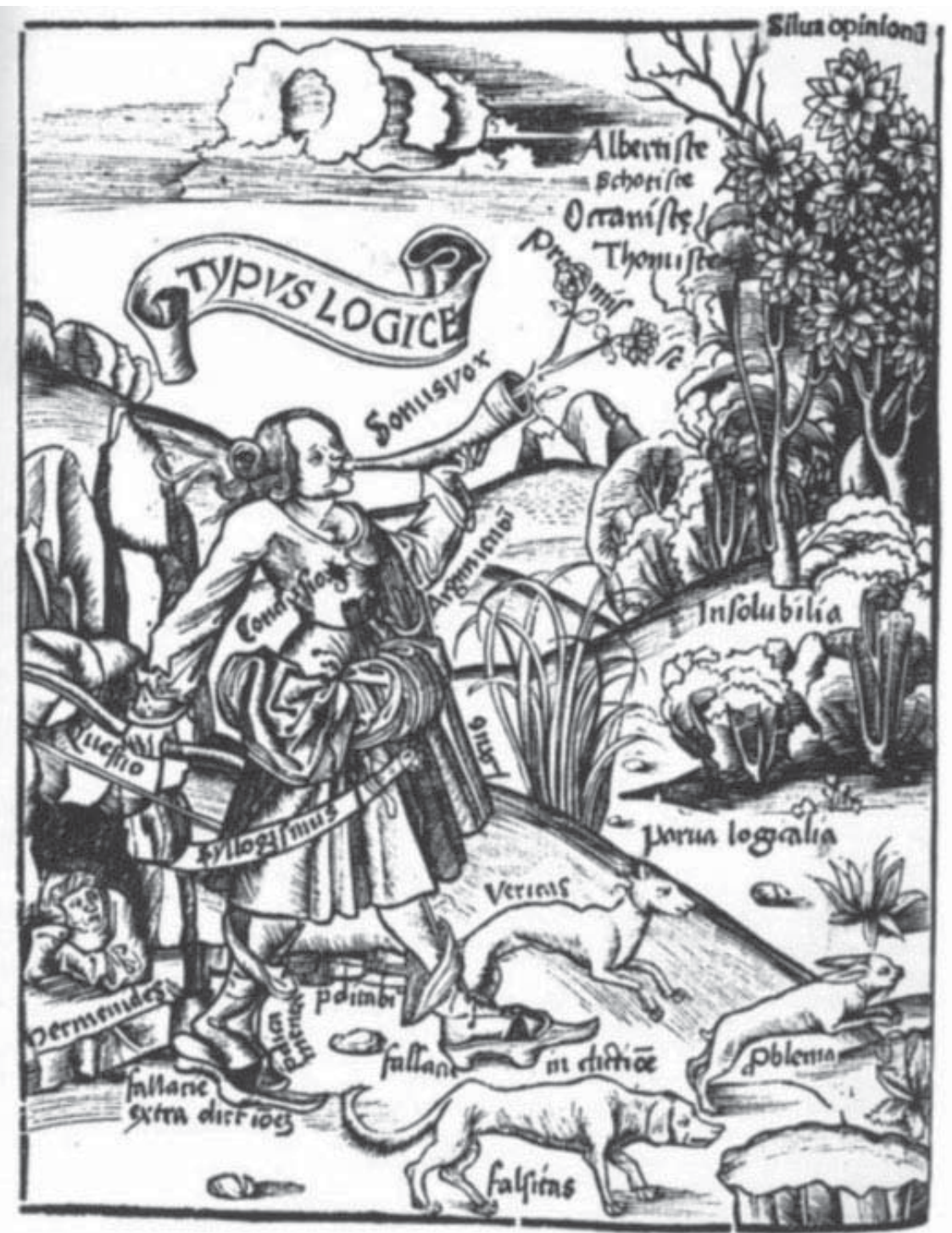

FIGURA 1 - Typus logice

Gregor Reisch. Margarita philosophica.

Argentorati: Grüninger, 1508. 
